\title{
Decreased Prefrontal Activity During a Cognitive Inhibition Task Following Violent Video Game Play: A Multi-Week Randomized Trial
}

\author{
Tom A. Hummer \\ and William G. Kronenberger \\ Indiana University School of Medicine
}

\author{
Yang Wang and Vincent P. Mathews \\ Medical College of Wisconsin
}

\begin{abstract}
There is substantial evidence that exposure to violent media increases aggressive thoughts and behaviors, potentially due in part to alterations to inhibitory mechanisms mediated by prefrontal cortex. Past research has demonstrated that playing a violent video game for short periods decreases subsequent prefrontal activity during inhibition, yet the impact of long-term game play is unclear. To assess how extensive video game play impacts brain activity, young adult males $(n=49$; ages $18-29)$ with limited video game experience performed a go/no-go task during fMRI for 3 consecutive weeks. Following a baseline scan, these men were randomly assigned to extensively play a violent video game (VG) or avoid all video game play (control) during the subsequent week. After 1 week, inhibition-related activity decreased in right inferior frontal gyrus and right cerebellum in the VG group, compared to the control sample, and selfreported executive functioning problems were higher. VG participants assigned to a second week of game play had similarly reduced bilateral prefrontal activity during inhibition, relative to the control group. However, VG participants assigned to avoid game play or play a cognitive training game during the second week demonstrated similar overall changes from baseline as the control group. This research provides preliminary evidence indicating how long-term video game play may impact brain function during inhibition, which may impair control of aggressive behavior.
\end{abstract}

Keywords: media violence, video game, fMRI, inhibition, prefrontal cortex, cognitive control, executive functioning

Supplemental materials: http://dx.doi.org/10.1037/ppm0000141.supp

Advances in the availability, design, and capabilities of video games have driven increasing rates of usage among both children and adults (Lenhart et al., 2008). These games are played for a variety of reasons, including entertainment, intellectual challenges, competitive drive,

Tom A. Hummer, Department of Psychiatry, Indiana University School of Medicine, and Department of Radiology and Imaging Sciences, Indiana University School of Medicine; William G. Kronenberger, Department of Psychiatry, Indiana University School of Medicine; Yang Wang and Vincent P. Mathews, Department of Radiology, Medical College of Wisconsin.

Correspondence concerning this article should be addressed to Tom A. Hummer, 705 Riley Hospital Drive, Riley Outpatient Center ROC 4300, Indianapolis, IN 46202. E-mail: thummer@iupui.edu and social interaction (Olson, 2010), but such extensive exposure raises questions about unintended consequences that can impact cognition and behavior, especially regarding enduring effects of video game play. One specific area of concern has been how long-term exposure to video game violence may have a long-lasting impact on the brain and behavior.

Concern about the potential effects of media violence has persisted for decades, and substantial correlational and experimental research has indicated a link between violent media exposure and more aggressive attitudes and behaviors (Anderson \& Bushman, 2001; Anderson et al., 2010; Greitemeyer \& Mügge, 2014; Paik \& Comstock, 1994) although some researchers posit that the strength of this relationship may be overstated (Ferguson \& Kilburn, 2009; 
Sherry, 2001), or that factors other than violence per se, such as game difficulty, may be more important (Engelhardt, Hilgard, \& Bartholow, 2015). The majority of research suggests that playing a violent video game for a short period results in increased aggressive cognitions and behavior, greater hostility, and decreased empathy immediately following gameplay compared with play of a nonviolent game (Anderson \& Dill, 2000; Barlett, Rodeheffer, Baldassaro, Hinkin, \& Harris, 2008; Bartholow \& Anderson, 2002; Bartholow, Sestir, \& Davis, 2005; Bushman \& Anderson, 2002; Uhlmann \& Swanson, 2004). In addition, longitudinal research has revealed that higher exposure to TV violence during childhood is related to more aggression during adulthood, even when controlling for levels of childhood violent behaviors (Huesmann, Moise-Titus, Podolski, \& Eron, 2003; Lefkowitz, Eron, Walder, \& Huesmann, 1977). Similar longitudinal effects have been reported with violent video games (Gentile, Li, Khoo, Prot, \& Anderson, 2014; Möller \& Krahé, 2009; Willoughby, Adachi, \& Good, 2012).

One major contributor to these effects on aggression may be poorer inhibitory control mechanisms that manage the expression of aggressive thoughts and behaviors (Granvald \& Marciszko, 2016; Poland, Monks, \& Tsermentseli, 2015; Van den Bergh, et al., 2006; Vigil-Colet \& Codorniu-Raga, 2004). For instance, a lowering of natural inhibitory processes (such as aversion from gore or violent acts) may be necessary to enjoy a violent film or succeed at a violent video game. Plus, high visual and emotional stimulation may encourage impulsive responding or may decrease sensitivity to low levels of stimulation, impairing executive processes such as attention. Indeed, performance on tests of executive function and self-control is worse among teens and young adults with higher levels of media violence exposure (Hummer, Kronenberger, Wang, Anderson, \& Mathews, 2014; Kronenberger, Mathews, Dunn, Wang, Wood, Giaque, et al., 2005a), indicating that the ability to inhibit aggressive responses may be impaired with repeated violent TV or video game exposure.

These inhibitory processes are typically mediated via prefrontal cortex, and if prefrontal capabilities are affected, such as if the brain is trained to respond more quickly or less cau- tiously, aggression may be more likely to occur following provocation. Neuroimaging techniques have examined the direct link between media violence exposure and its impact on the brain. For example, self-reported levels of past media exposure were related to altered anterior cingulate and dorsolateral prefrontal activity during a Stroop task (Mathews et al., 2005) and to lower orbitofrontal cortex thickness (Strenziok et al., 2010). Watching violent film clips results in progressively reduced responses in orbitofrontal and frontoparietal regions over the course of an experiment (Kelly, Grinband, \& Hirsch, 2007; Strenziok et al., 2011) or lower insula responses to subsequent painful scenes, suggesting neural desensitization (Guo et al., 2013).

Further evidence suggests that playing a violent video game, compared to a nonviolent game, reduces subsequent prefrontal cortex (PFC) activity (Hummer et al., 2010; Wang et al., 2009) and increases limbic responses (Wang et al., 2009). Using event-related brain potential (ERP) methods, individuals who played a violent game had a diminished P300 amplitude to violent images, and this reduced brain response was associated with more aggressive responses in a subsequent competitive task (Bartholow, Bushman, \& Sestir, 2006; Engelhardt, Bartholow, Kerr, \& Bushman, 2011). Taken together, this research indicates that prefrontal control mechanisms may be altered and/or impaired by play of violent video games. Because top-down control of behavior and emotional responses are mediated in large part by PFC, alterations to its function may have significant long-term effects on inhibitory processes, including the control of aggression, behavior, and attention.

There is also substantial research that has examined how playing action video gamesoften violent in nature-may improve neurocognitive functioning. The most consistent effects in these studies are improvements to visuospatial processing (Boot, Kramer, Simons, Fabiani, \& Gratton, 2008; Dye, Green, \& Bavelier, 2009; Green \& Bavelier, 2003; Powers, Brooks, Aldrich, Palladino, \& Alfieri, 2013; Spence \& Feng, 2010), including spatial imagery or mental rotation abilities, sometimes deemed to reflect attention capabilities. At first pass, these lines of research seem to conflict, but it would be more accurate to conclude that the 
wide range of effects merely reflects the complex nature of video games and the variety of manners to assess neurocognitive function. Playing violent action video games, for instance, could simultaneously reduce inhibitory capabilities while increasing perceptual or spatial awareness. Neuroimaging techniques may help clarify how video game play affects the allocation of neural resources.

A key question of these investigations is to determine how persistent violent video game play, particularly during childhood and adolescence, may affect long-term neurodevelopment and behavior. This question poses a difficulty for potential research, as a true experimental approach —random assignment to solely play or avoid violent video games for several years during development-is ethically impermissible. Therefore, to understand long-term effects of violent video game play on neural inhibitory mechanisms, it is necessary to combine longterm correlational research and short-term $(\sim 30$ min) experiments with abbreviated "long-term" in vivo experiments.

To address this latter investigative method, we conducted a repeated-measures, multiweek functional MRI (fMRI) investigation of young adult males with minimal video-game experience. Participants were randomly assigned to play a violent video game extensively for one week (VG) or to refrain from game play. At a baseline session and at the end of each experimental week, they performed a cognitive inhibition task during fMRI. Subsamples of the VG group were assigned to a second week of game play (VG2), or to refrain from all video games (VG1) or play a working memory cognitive training game (CT) during the second experimental week. Based on prior findings using brief exposure to violent video game play (Hummer et al., 2010; Wang et al., 2009), we hypothesized that extensive play of the violent game would reduce activity in prefrontal regions involved in behavioral and cognitive control, which would be reversed by the cognitive training game.

\section{Method}

\section{Participants}

Seventy-three young adult male participants (aged 18-29; Table 1) took part in this study.
Participants were required to have an IQ $>70$, to be free of neurological conditions or MRI contraindications, and to be judged to be psychiatrically healthy, based on responses on the Adult Self-Report Inventory (Gadow, Sprafkin, \& Weiss, 2004) and self-reported psychiatric history. Individuals could not have a current or past diagnosis of attention-deficit/hyperactivity disorder (ADHD), bipolar disorder, or disorder involving psychosis, nor could these be present in any first-degree relative. Participants selfreported playing an average of five hours a week or less of video games during the past year, and specifically two hours a week or less of violent game play. Only men were included to eliminate sex as a potential moderator variable in the present investigation and because most adult violent video game players are men (Dunlap, 2013; Lenhart et al., 2008; Nielsen, 2014; Rideout, Foehr, \& Roberts, 2010).

\section{Procedure}

Participants had a total of four study visits: an initial baseline/screening session and three subsequent sessions with an fMRI scan (see Figure 1). The first visit was 4-10 days prior to the second, and each subsequent visit occurred following a one week ( \pm 1 day) interval. A participant's three scanning sessions took place at the same time of day ( \pm 1 hour). Approval for all study procedures was provided by the university institutional review board (IRB).

During the first visit, participants provided informed consent, completed screening information, answered questionnaires, and completed the K-BIT-2 Matrices subtest (Kaufman \& Kaufman, 2004) to establish nonverbal IQ. A preassignment version of the Video Game Rating Index (VRI; Wang et al., 2009) was provided at Visits 1 and 2 (scores were averaged) to assess past skill and experience, and a postassignment VRI at Visits 3 and 4 measured familiarity, excitement, interest, difficulty, and violence with the assigned game. The Media Exposure Measure (MEM; Kronenberger et al., 2005a, 2005b) required participants to estimate past-year exposure to different media, via an anchored 0-9 scale, and the level of violent content in the programming (from $0-$ Not present/Very rare to 3-Most of the time).

Several measures determined whether behavior or executive functions were altered through- 
Table 1

Demographics and Baseline Characteristics

\begin{tabular}{lccccc}
\hline & & \multicolumn{3}{c}{ VG subsamples } & Cog train \\
\cline { 3 - 4 } & Control & VG & VG1 & VG2 & $23.8(3.5)$ \\
Age & $24.1(4.0)$ & $23.1(3.4)$ & $22.4(4.0)$ & $23.2(2.8)$ & $114.1(11.8)$ \\
Nonverbal IQ & $111.6(14.8)$ & $110.1(12.2)$ & $104.5(11.8)$ & $112.8(11.6)$ & $4.1(.7)$ \\
Video game skill & $3.4(1.1)$ & $3.8(.9)$ & $3.6(1.2)$ & $3.8(.8)$ & $3.3(1.2)$ \\
Video game experience & $3.0(1.3)$ & $3.2(.9)$ & $3.2(1.1)$ & $3.2(.4)$ & $1.1(.7)$ \\
Weekly violent VG play (hrs) & $1.1(.9)$ & $1.0(.7)$ & $1.0(.7)$ & $1.0(.7)$ & $1.5(1.3)$ \\
Weekly total VG play (hrs) & $2.1(1.3)$ & $2.0(1.3)$ & $1.8(1.4)$ & $2.6(1.1)$ & $5.7(1.6)$ \\
MEM past-year total media & $6.0(.78)$ & $5.5(1.6)$ & $5.4(1.6)$ & $5.1(1.6)$ & $4.9(3.1)$ \\
MEM past-year media violence & $5.3(2.8)$ & $4.5(3.0)$ & $5.5(3.2)$ & $3.3(2.5)$ & 50.0 \\
Past Call of Duty 4 Exp (\%) & 64.3 & 48.6 & 53.8 & 41.7 & 70.0 \\
Any past Call of Duty Exp (\%) & 78.6 & 65.7 & 69.2 & 58.3 & $5.3(2.1)$ \\
& & Baseline week & & & $4.4(4.7)$ \\
MEM TV Viewing Time & $6.0(1.3)$ & $5.3(2.0)$ & $5.2(2.0)$ & $5.4(2.0)$ & $6.4(3.1)$ \\
MEM TV Violence Score & $3.8(4.2)$ & $3.5(3.9)$ & $3.3(3.7)$ & $2.9(3.4)$ & $4.0(3.9)$ \\
PSQI Sleep Quality & $7.9(2.5)$ & $8.2(4.0)$ & $8.9(4.4)$ & $9.0(8.8)$ \\
BRIEF Inhibit & $44.8(6.6)$ & $42.8(6.7)$ & $41.3(6.2)$ & $43.8(5.4)$ & $43.6(5.0)$ \\
BRIEF Emot Control & $44.2(7.3)$ & $43.0(5.7)$ & $42.2(6.6)$ & $44.0(5.0)$ & $43.0(5.8)$ \\
BRIEF GEC & $44.0(6.2)$ & $42.6(7.9)$ & $40.8(8.4)$ & $44.7(7.4)$ & $42.6(8.0)$ \\
\hline
\end{tabular}

Note. The Media Exposure Measure (MEM) past-year and weekly media scores reflect self-reported exposure on an anchored 0 ("None at all") to 9 ("More than 35 hours per week") scale. A score of 5 indicates "About 7 hours per week" and 6 indicates "About 14 hours per week." VG = Video game group; VG1 = One week video game subsample; VG2 = Two week video game subsample; Cog Train = One week video game, one week cognitive training game subsample; PSQI = Pittsburgh Sleep Quality Index; BRIEF = Behavioral Rating Index of Executive Function; DMD = Daily Media Diaries.

out the week by video game play. Participants were provided daily media diaries with which to report levels of various media exposure, in an identical manner as the MEM, during each day at home between scan sessions. At each visit, the Pittsburgh Sleep Quality Index (Buysse, Reynolds, Monk, Berman, \& Kupfer, 1989) was also completed to monitor sleep quality or tiredness, and the Behavior Rating Index of Executive Function (BRIEF; Gioia, 2000) quantified executive functions in daily life.

Following Visit 1, participants were told to refrain from playing any video game until their next visit, including console, computer, and smartphone games. At the second visit, participants completed media questionnaires and were randomized to one of the four groups: controls (C); one week of video game play (VG1); two weeks of video game play (VG2); or one week of video game play followed by a week of the cognitive training game (T). Participants in the three video game conditions were provided a laptop (Dell Inc., Round Rock, Texas) loaded with Call of Duty 4: Modern Warfare (Activision, Santa Monica, California). This game is a first-person shooting game chosen due to its popularity and high violent content. Participants were instructed to play the game for $\sim 1-1.5$ hours each day before the next visit $(\sim 7-14$ hours total). Game play took place away from the laboratory, at the subject's own discretion, on single-player mode. A monitoring system recorded computer usage and minutes of game play. Those in the control group were not provided a laptop and were instructed to continue avoiding game play of all types.

At the third visit, the laptop was checked to ensure video game time requirements had been met. The laptop was returned to the VG2 group with identical instructions for the subsequent week (between scans 2 and 3; Figure 1). The T group was provided a new laptop loaded with Cogmed, a working memory training program that involves multiple distinct working memory games designed to improve executive functioning (www.cogmed.com; Pearson Clinical Assessment, San Antonio, TX). These games involve simple button-press tasks that require subjects to maintain multiple items in working memory, such as keeping track of the order that 


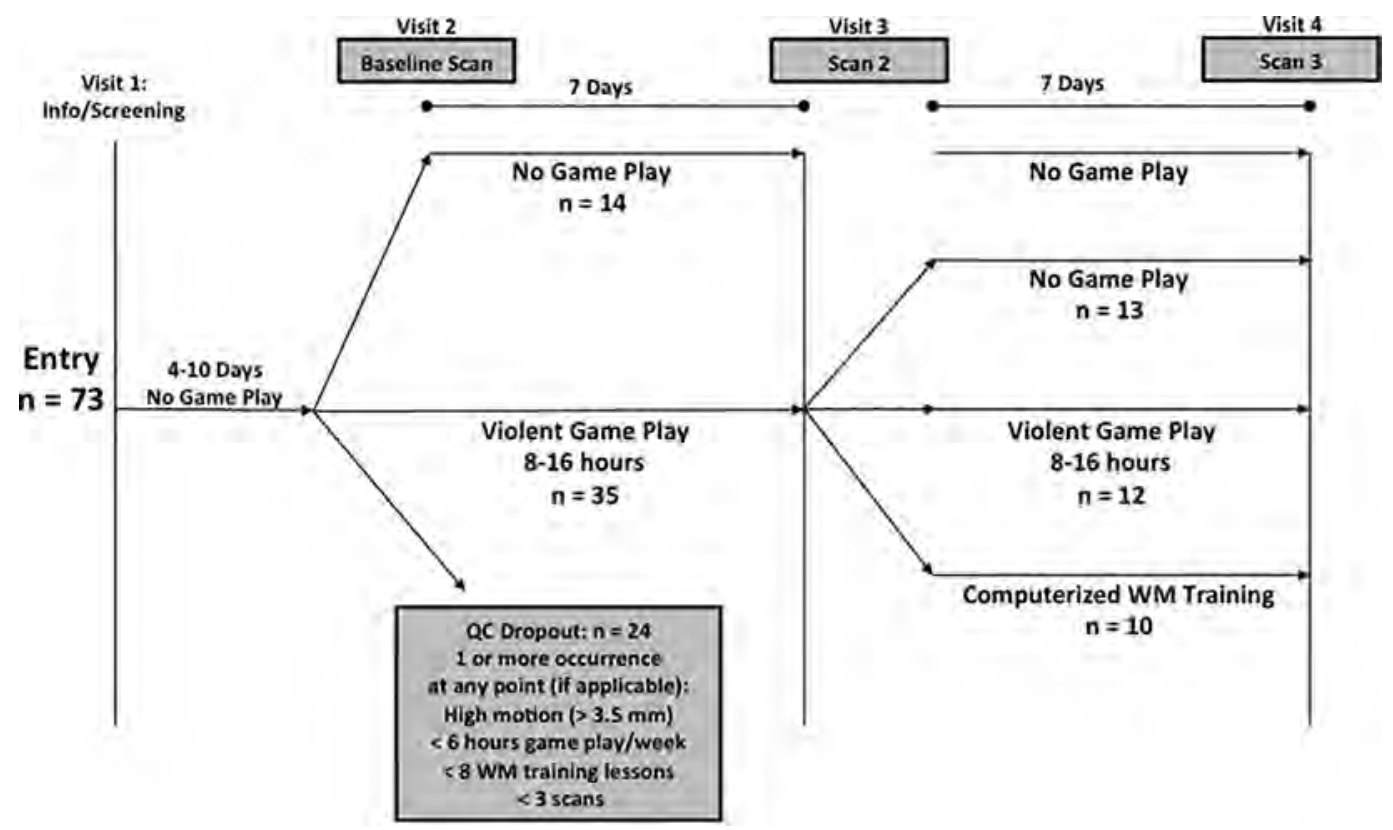

Figure 1. Experimental design.

lights flash. These games are adaptive, with difficulty increasing as subject performance improves, and last several minutes each, with multiple games comprising a single "lesson." Participants were required to complete at least eight lessons before the next visit, which were anticipated to last $\sim 30-45 \mathrm{~min}$ each during the actual exercises, plus 5-15 min in log-on time and rest between exercises. Those in the VG1 and control samples refrained from any video game play for the next week.

\section{fMRI Protocol}

The first fMRI session took place during the second study visit. The protocol for the scanning session was identical for each scanning visit. Scans took place on a 3T Siemens TIM Trio scanner with an eight-channel head coil (Siemens, Erlangen, Germany). A threedimensional T1-weighted magnetization-prepared rapid acquisition gradient echo anatomical scan was performed prior to any functional data acquisition, with $1 \times 1 \times 1.2 \mathrm{~mm}$ voxel size. To examine brain activity during cognitive inhibition, participants performed a Go/No-go task during a $\mathrm{T}^{*}$-weighted functional scan lasting 7:36, with 39 axial slices acquired with online motion correction; voxel size of $2.5 \times$ $2.5 \times 3.5 \mathrm{~mm}$; TR: $2250 \mathrm{~ms}$; TE: $29 \mathrm{~ms}$; Flip Angle $79^{\circ}$; and FOV: $220 \times 220 \mathrm{~mm}$.

\section{Go/No-go Task}

The Go/No-go task has been extensively used in fMRI research to examine brain activity during inhibitory control, revealing activity in a bilateral fronto-parietal network during inhibition of button-press responses (Konishi et al., 1999; Liddle, Kiehl, \& Smith, 2001). In the Go/No-go task used here, participants were presented with a series of letters, one at a time, shown via E-prime software (Psychological Software Tools, Inc., Pittsburgh, PA) and viewed through goggles during the scan. Participants were told to respond with a button press (Go) to all stimuli, unless the presented letter was " $\mathrm{X}$ " (No-go). Letters were presented in a pseudorandomized order. Go trials comprised $75 \%$ of stimuli, presented at an average of 1 per 1.7 seconds, and No-go trials were presented at a rate of 1 per 5.1 seconds. Reaction time and accuracy measures were recorded. The Go/ No-go paradigm was identical each week, except for the actual presented letters. Participants 
practiced the task for one minute prior to the scan at each session.

\section{Data Analysis}

Twenty-four of 73 participants were removed from analysis due to quality control measures. For instance, if participants did not play the violent video game for at least 6 hours for any week of the study when directed or complete at least eight cognitive training lessons (for the $\mathrm{T}$ group), their data were excluded. In addition, participants with greater than $3.5 \mathrm{~mm}$ (one voxel) absolute displacement at any point during the fMRI task, at any visit, were removed from analysis (see Results for breakdown of exclusion criteria by group). Primary analyses were focused on how one or two weeks of video game play influenced brain activity during cognitive inhibition, and additional analyses examined how alternatives to a second week of video games influenced the brain. Behavioral and media exposure data were analyzed with repeatedmeasures ANOVAs (group-by-session) with SPSS 21 (IBM, Armonk, NY).

\section{fMRI Analysis}

Neuroimaging data were analyzed with the AFNI software package (Cox, 1996). Each subject's blood oxygenated level-dependent (BOLD) time series was slice-time corrected and aligned to his structural data. The functional data were spatially smoothed with a 5-mm full width at half maximum Gaussian kernel and motion-corrected by aligning the time series to the first time-point. AFNI's despiking algorithm reduced time series outliers.

Trials were separated by response accuracy and type, creating four distinct conditions: Correct Go, Incorrect Go, Correct No-go, and Incorrect No-go, modeled from the onset of each stimulus presentation. Each condition was convolved with a gamma-based hemodynamic response function, resulting in a model BOLD time series for each trial type. To identify the contribution of each condition to the BOLD signal, these ideal time series were used as regressors, along with motion parameters of no interest and baseline constant, linear, and quadratic terms. The coefficient contrast of interest is Correct No-go-Correct Go. For group comparisons, these individual results were trans- formed to a standardized brain (Talairach \& Tournoux, 1988).

Our primary hypotheses were focused on changes to lateral prefrontal activity during inhibition. Therefore, we established bilateral inferior prefrontal ROIs, based on a meta-analysis of Go/No-go fMRI investigations (Swick, Ashley, \& Turken, 2011). A 10-mm sphere was created around two voxels (Right: $(34,22,0)$; Left: $(-30,14,0))$ reflecting the peak prefrontal activity during inhibition, as determined with this meta-analysis. These ROIs were further bounded within each subject by a whole-brain functional mask created from the participant's BOLD time series. For each participant, the mean Correct No-go-Go response within these ROIs was then calculated for each scan for repeated-measures ANOVA tests (side-bycondition-by-time).

In addition, whole-brain voxel-wise analyses were also conducted with repeated-measures ANOVAs (condition-by-time). To correct for multiple comparisons, Monte Carlo analyses were conducted to determine the appropriate clustersize threshold for significance (voxel-level $p<$ $.01 ; 162$ contiguous voxels for corrected $p<.05$ ), using mean smoothness of regression residuals from individual subject data.

\section{Results}

Data from 24 participants (3 C, 7 VG1, 6 VG2, $8 \mathrm{~T}$ ) were excluded due to failure to complete all three scans as scheduled (2 C, 3 VG1, 2 VG2, 4 $\mathrm{T}$ ), to follow study guidelines (such as not playing at least six hours/eight lessons of the assigned game; $3 \mathrm{VG} 1,4 \mathrm{VG} 2,5 \mathrm{~T}$ ), or due to high motion during any of the three scans (1 C, 1 VG1, 2 VG2, 1T; some subjects were excluded for multiple reasons), resulting in 49 participants included in data analysis (see Figure 1). The sample was low in baseline self-reported total and violent videogame play, as required by inclusion criteria (see Table 1). A little over half of participants reported some experience playing the assigned video game, though 69\% had experience with any Call of Duty game, with no difference between groups for both two-group (C vs. VG) and four-group comparisons (all $\chi^{2}<1.00 ; p>.36$ ). Video game players averaged $10.5 \pm 2.8$ (mean \pm standard deviation) hours of game play during the week following Visit 2 and $10.8 \pm 3.2$ hours (VG2) following Visit 3. The CT group averaged $10.1 \pm 0.9$ les- 
sons during their cognitive training week. During the study, those in the video game groups rated their experiences to be highly violent and engaging on 10-pt scales (see Table 2).

Assignment to a video game condition did not significantly alter TV viewing habits (see Table 2), with average daily TV viewing ratings corresponding to $1-2+$ hours for each group (scores of 4 indicate "30 minutes or more" and 6 indicates " 2 hours or more"). Sleep quality was also not affected by condition.

There were no significant differences in BRIEF scores at baseline, but responses were influenced by assigned video game condition. Subjects in the VG group reported more executive function difficulties after a week of game play, as revealed by significant group-bysession interactions for emotional control, $F(1$, $47)=7.81, p=.008$, and Global Executive Composite (GEC) scores, $F(1,47)=5.19, p=$ .03 (Table 2). An interaction was also present after the second experimental week (emotional control: $F(6,90)=3.17, p=.007$; GEC: $F(6$, $90)=2.87, p=.01)$, although a mixed picture was formed, with control and VG2 groups showing a bigger drop from baseline levels than the other two groups (see Table 2).

\section{Behavioral Performance}

Participants remained largely similar in performance on the Go/No-go task throughout the investigation. There were no significant differences in reaction time (RT) (Go trials) or in accuracy during Go or No-go trials between groups at any time point (Suppl. Figure 1), and ANOVA tests revealed no significant effects of group or interactions (all $F<1.84, p>.18$ ).

\section{Neuroimaging}

Across all groups, the Go/No-go task robustly activated a frontoparietal network during the baseline scan (before randomization), consistent with prior research (Figure 2; see Table

Table 2

Effects of Video Game Condition on Media Consumption, Sleep, and Executive Function

\begin{tabular}{|c|c|c|c|c|}
\hline Scan 2 visit & Control & VG & & \\
\hline \multicolumn{5}{|l|}{ Change from baseline } \\
\hline MEM TV Viewing Time & $-0.6(1.0)$ & $-0.6(1.4)$ & \multicolumn{2}{|c|}{$\uparrow=$ more $\mathrm{TV}$} \\
\hline MEM TV Violence & $-1.2(2.5)$ & $-0.7(4.3)$ & \multicolumn{2}{|c|}{$\uparrow=$ more violent $\mathrm{TV}$} \\
\hline PSQI Sleep Quality & $-0.1(2.3)$ & $-0.2(2.3)$ & \multicolumn{2}{|c|}{$\uparrow=$ better sleep } \\
\hline BRIEF Inhibit & $+0.5(2.2)$ & $-0.0(3.2)$ & \multicolumn{2}{|c|}{$\uparrow=$ worse inhibition } \\
\hline BRIEF Emotional Control* & $-1.1(3.4)$ & $+1.2(2.1)$ & \multicolumn{2}{|c|}{$\uparrow=$ worse control } \\
\hline BRIEF Global Exec Composite* & $-1.7(2.7)$ & $+0.1(2.1)$ & \multicolumn{2}{|c|}{$\uparrow=$ worse exec function } \\
\hline \multicolumn{5}{|l|}{ Video game Ratings } \\
\hline Engaging score & - & $8.0(.7)$ & & \\
\hline Violence score & - & $9.8(.5)$ & & \\
\hline Hours of game play & - & $10.5(2.7)$ & & \\
\hline Scan 3 visit & Control & VG1 & VG2 & Cog train \\
\hline \multicolumn{5}{|l|}{ Changes from baseline } \\
\hline DMD TV Viewing Time & $-1.1(1.6)$ & $-0.2(2.2)$ & $-0.6(.9)$ & $+0.1(1.4)$ \\
\hline DMD TV Violence & $-1.1(3.5)$ & $+0.5(3.9)$ & $-1.0(2.4)$ & $0(2.4)$ \\
\hline PSQI Sleep Quality & $+1.5(4.0)$ & $+2.2(3.4)$ & $+0.3(2.8)$ & $+1.5(2.5)$ \\
\hline BRIEF Inhibit & $-1.1(3.5)$ & $+0.1(3.9)$ & $-1.4(4.4)$ & $+1.6(4.0)$ \\
\hline BRIEF Emotional Control* & $-1.6(2.8)$ & $+0.9(2.2)$ & $-0.7(2.5)$ & $+1.7(3.8)$ \\
\hline BRIEF Global Exec Composite* & $-2.6(3.6)$ & $-0.2(2.0)$ & $-2.9(3.4)$ & $+0.4(3.1)$ \\
\hline \multicolumn{5}{|l|}{ Video game Ratings } \\
\hline Engaging score & - & - & $8.2(.8)$ & - \\
\hline Violence score & - & - & $9.8(.4)$ & - \\
\hline Hours of game play & - & - & $10.8(3.2)$ & - \\
\hline
\end{tabular}

* Significant Group-by-Session interaction $(p<.05) . \mathrm{VG}=$ Video game group; VG1 = One week video game subsample; VG2 = Two week video game subsample; Cog Train = One week video game, one week cognitive training game subsample; PSQI = Pittsburgh Sleep Quality Index; BRIEF = Behavioral Rating Index of Executive Function; DMD = Daily Media Diaries. 

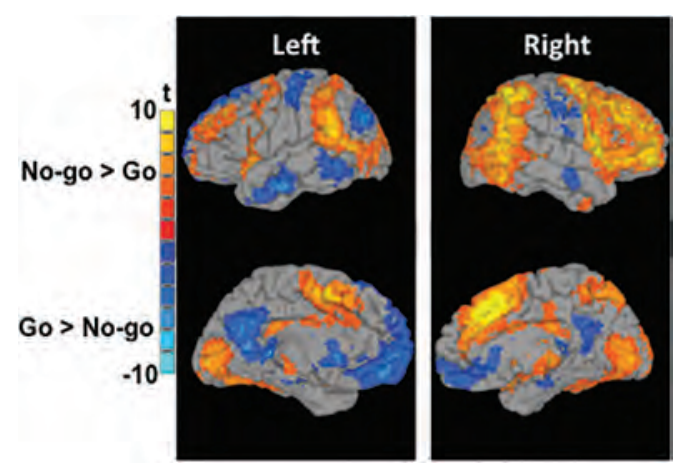

Figure 2. Baseline scan activity. No-go-Go activity collapsed across all groups for the baseline scan (voxels significant at $p<.01$, clusters larger than 162 contiguous voxels for corrected $p<.05$ ).

3 for summary of results). As expected, the BOLD response was higher during cognitive inhibition in bilateral inferior prefrontal regions (where ROIs were formed) and in parietal cortex (see Figure 2).

\section{One Week of Game Play}

After one week of video game play, activity in right cerebellum was significantly altered (see Figure 4), as revealed via whole-brain repeated-measures ANOVA. In this cluster, inhibition-related activity increased in the control group and decreased in the VG group after a week of play. In addition, the ROI analysis indicated that prefrontal activity decreased from baseline in the VG group, relative to the control group (group-by-session interaction: $F(1,47)=$ $4.195, p=.046$; Figure 3). Post hoc tests with each ROI indicated similar trends for pre/post differences on both the right $(F(1,47)=4.026$, $p=.051$; Cohen's $d=0.64)$ and left sides $(F(1$, $47)=3.395, p=.072$; Cohen's $d=0.54)$.

\section{Two Weeks of Game Play}

Whole-brain $3 \times 4$ (time $\times$ group) ANOVA tests with all groups combined revealed no significant group-by-time interactions after correcting for multiple comparisons. However, focused analyses revealed that two weeks of violent video game play (C vs. VG2) was associated with bilateral decreases in prefrontal activity during cognitive inhibition. Whole-brain analyses indicated that No-go activity decreased significantly more in the VG2 group in both left and right lateral prefrontal clusters (see Figure

Table 3

Summary of Neuroimaging Results

\begin{tabular}{|c|c|c|c|c|}
\hline Region & BA & Talairach peak & Peak t & Cluster size \\
\hline \multicolumn{5}{|l|}{ Baseline (all groups combined) } \\
\hline \multicolumn{5}{|l|}{ No-go $>$ Go } \\
\hline L/R Insula & $6 / 8 / 9 / 10 /$ & $(35,17,2)$ & 13.40 & 30,285 \\
\hline Caudate & $32 / 44 / 45$ & & & \\
\hline \multicolumn{5}{|l|}{ Dorsal Anterior Cingulate Cortex } \\
\hline \multicolumn{5}{|c|}{ Inferior/Middle/Superior Frontal Gyrus } \\
\hline L/R Precuneus & $7 / 18 / 19$ & $(27,-61,38)$ & 11.98 & 29,114 \\
\hline \multicolumn{5}{|l|}{ Inferior Parietal Lobule } \\
\hline \multicolumn{5}{|l|}{ Occipital Cortex } \\
\hline L Superior Temporal Sulcus & 22 & $(-51,-25,2)$ & 4.82 & 251 \\
\hline \multicolumn{5}{|l|}{ Go $>$ No-go } \\
\hline Posterior Cingulate Cortex & $23 / 30$ & $(25,-43,18)$ & 9.52 & 12,175 \\
\hline L Postcentral Gyrus & $3 / 4$ & $(-45,-21,52)$ & 6.90 & 951 \\
\hline L Middle Temporal Gyrus & $20 / 21$ & $(-59,-5,-20)$ & 7.47 & 569 \\
\hline L Middle Temporal Gyrus & 21 & $(-63,-43,-6)$ & 6.97 & 308 \\
\hline R Precentral Gyrus & $4 / 6$ & $(61,-3,30)$ & 5.18 & 215 \\
\hline \multicolumn{5}{|l|}{ R Postcentral Gyrus } \\
\hline \multicolumn{5}{|c|}{ After 1 week Control $($ No-go-Go) $>$ VG (No-go-Go) } \\
\hline R Cerebellum & & $(25,-65,-38)$ & 4.77 & 182 \\
\hline \multicolumn{5}{|c|}{ After 2 weeks Control (No-go-Go) $>$ VG2 (No-go-Go) } \\
\hline L Middle Frontal Gyrus & $10 / 46$ & $(-43,41,22)$ & 3.13 & 194 \\
\hline R Middle Frontal Gyrus & 9 & $(27,41,36)$ & 4.51 & 177 \\
\hline
\end{tabular}



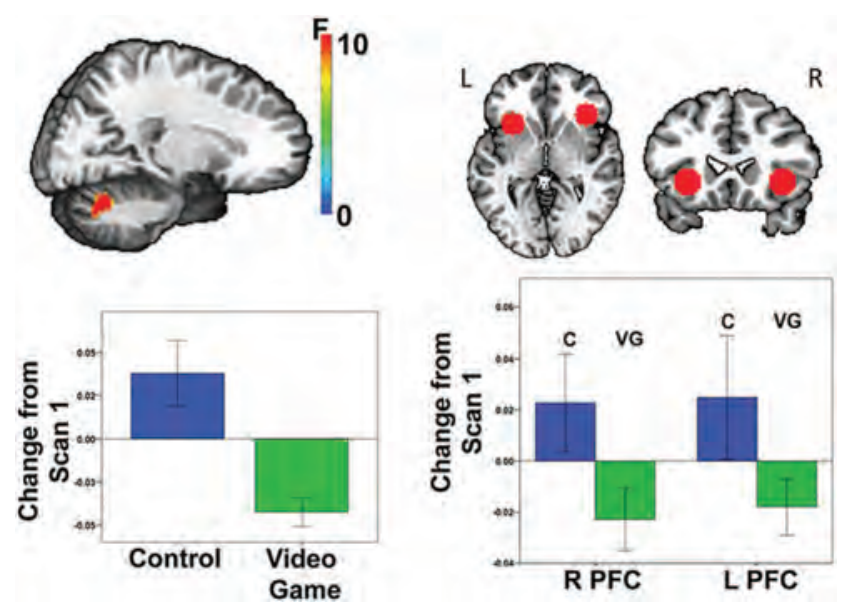

\begin{abstract}
Figure 3. Effect of one week of violent video game play. Significant Group-by-Session interaction of No-go-Go contrast from whole-brain analysis depicted on left $(p<.05$, corrected for multiple comparisons). Right image depicts structural right inferior frontal gyrus ROI. Bar graph shows mean beta changes from baseline scan in each cluster (error bars are \pm 1 standard error).
\end{abstract}

4) compared to the control group, with no other significant differences.

In addition, ANOVA tests with ROI data from all groups did reveal a significant groupby-session interaction, $F(6,90)=2.23, p=$ .047 ; Figure 4 . This effect was largely driven by the significant drop in prefrontal activity in the VG2 group across the two experimental weeks, particularly on the right side (change from scan 1 , VG2 vs. C: right $t=2.55, p=.02$, Cohen's $d=1.0 ;$ left $t=1.04, p=.31$, Cohen's $d=$ 0.42 ); there were also general (nonsignificant) increases in prefrontal activity with reductions in video game play (the first week for the $\mathrm{C}$ group and the second week for the VG1 group), though specific session-to-session changes within subgroups were mostly nonsignificant (see Figure 4). In addition, cognitive training did not significantly alter prefrontal activity.

Within video game groups, exploratory forward regression models were conducted to examine what media and executive function characteristics were most closely associated with prefrontal ROI changes after one week (all VG subjects). Variables in the selection model included general and game-specific video game characteristics derived from the VRI at baseline and following game play (see Table 1), changes in BRIEF Inhibit, Emotional Control, and GEC index between sessions, and total duration of game play. On both the right and left sides, the greatest decreases in prefrontal activity after one week occurred in those participants reporting the lowest general video game expertise on the VRI (right: $\beta=.51, t=3.41, p=.002$; left: $\beta=.37, t=2.30, p=.028)$. In other words, the largest prefrontal changes were in the most video-game naïve subjects.

\section{Discussion}

This experimental fMRI investigation examined how increased play of a violent video game may alter brain activity. We present evidence that young adult males with low prior video game experience have reduced lateral prefrontal and cerebellum activity during cognitive inhibition after playing a violent video game extensively over a period of one week. In addition, bilateral prefrontal effects persisted after a second week of game play, though refraining from game play or playing a cognitive training game during this second week did not alter prefrontal activity.

Identifying early indicators for how extensive game play affects the brain may improve our understanding of potential long-term effects on brain function. Reduced prefrontal activity during inhibition following one or two weeks of violent video game play indicates that excessive 


\section{Control vs. VG2}
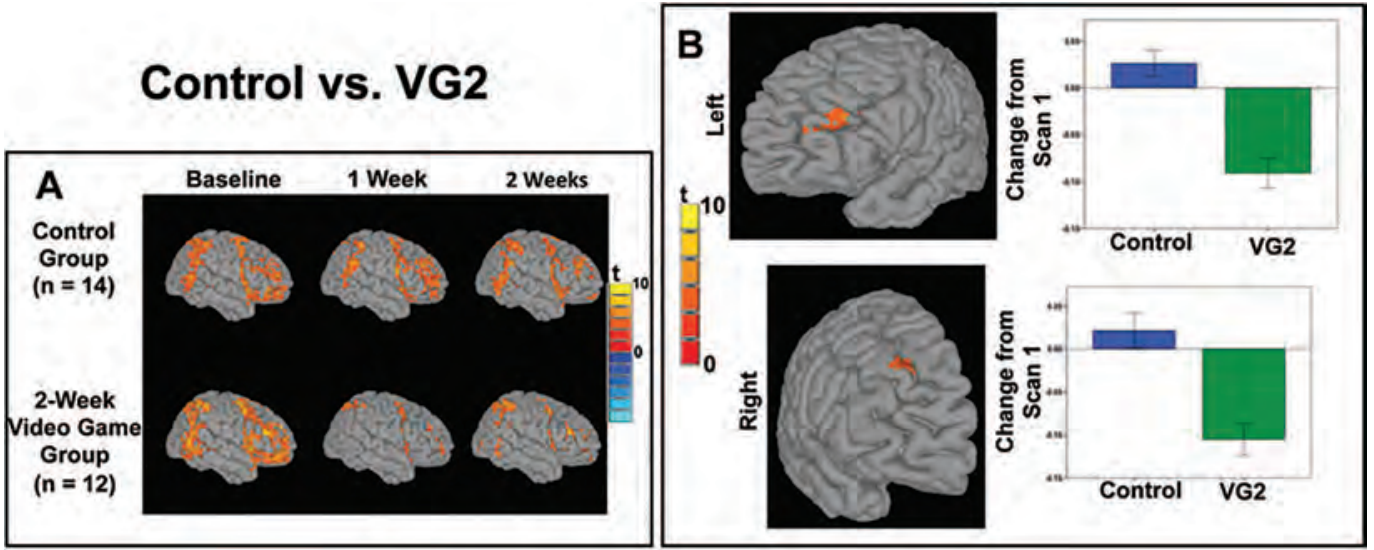

All Conditions - ROI Analysis

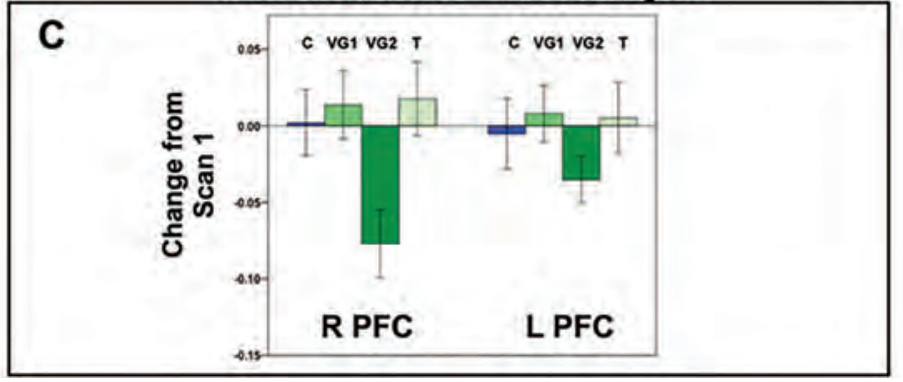

Figure 4. Effect of two weeks of violent video game play. (A) No-go-Go activity for individuals playing no video game (Control) or two weeks of a violent game (VG2) at each scan (voxels significant at $p<.01$, clusters larger than 162 contiguous voxels for corrected $p<.05$ ); (B) Mean beta changes in clusters showing a significant effect of two weeks of game play (Control vs. VG2); (C) Bilateral ROI activity (C: 2 weeks of no game play; 1 week of game play, 1 week of no game play; VG2: 2 weeks of game play; T: 1 week of game play, 1 week of cognitive training game).

game play may have long-term consequences on prefrontal function, although without a nonviolent game comparison group, we are unable to specifically ascribe effects to video game violence in this study. The prefrontal cortex, especially lateral regions, provides top-down control of motor or limbic (emotion-sensitive) brain regions (Aron, 2007; Ochsner \& Gross, 2005). Because prefrontal brain regions are the latest to fully mature (Huttenlocher, 1979; Lebel, Walker, Leemans, Phillips, \& Beaulieu, 2008; Sowell, Thompson, Holmes, Jernigan, \& Toga, 1999; Tunbridge et al., 2007), they may be especially susceptible to potential long-term effects during childhood and adolescence.

Lower prefrontal cortex function during inhibition is often associated with poorer inhibitory control. For instance, lower PFC activity or frontolimbic connectivity is present in clinical samples with inhibitory deficits, such as ADHD (Asahi, Okamoto, Okada, Yamawaki, \& Yokota, 2004; Pliszka, Liotti, \& Woldorff, 2000; Rubia, Smith, Brammer, Toone, \& Taylor, 2005; Yang et al., 2011) or problematic video game play (Luijten, Meerkerk, Franken, van de Wetering, \& Schoenmakers, 2015). That said, prefrontal activity changes can be interpreted in multiple ways. These changes may represent a decreased capacity for prefrontal function or an allocation of neural resources away from prefrontal cortex. These interpretations align with different mechanisms of inhibitory control: active inhibition, in which the direct prefrontal capabilities are compromised; or passive inhibition, in which resources are less focused on controlling cognition or behavior 
(Hofmann, Schmeichel, \& Baddeley, 2012; Munakata et al., 2011). A third possibility is that lower prefrontal cortex activity reflects more efficient processing (i.e., less energy expenditure) by the region, suggesting microlevel structural changes or alterations to the timing of the inhibitory process, neither of which could be detected with the current paradigm.

Because there was no nonviolent game group during the first experimental week, we cannot specifically attribute changes in brain activity to violent aspects of the game in this study. It is possible that simply playing any video game extensively, particularly one with high levels of action and excitement, would have a similar effect. Other research has typically found that action or violent video game play is related to improved performance on visually demanding tasks (e.g., spatial awareness, mental rotation; Chisholm, Hickey, Theeuwes, \& Kingstone, 2010; Green \& Bavelier, 2003, 2012; Spence \& Feng, 2010), while impulsivity or inhibitory control is often worse (Bailey, West, \& Anderson, 2010; Bailey, West, \& Kuffel, 2013; Gentile, Swing, Lim, \& Khoo, 2012; Hummer et al., 2014; Kronenberger et al., 2005a). In the brain, Bavelier, Achtman, Mani, and Föcker (2012) found increasing activity in visual attention regions as visuospatial load grew in individuals with little action video game experience (compared with those playing $5+$ hours/week, many of which were violent games). Similarly, a separate investigation found that nonvideo game players had a greater neural response to nonattended peripheral stimuli (Mishra, Zinni, Bavelier, \& Hillyard, 2011). These differences to visuospatial information processing likely reflect the set of skills that improve performance during many action video games.

These studies may represent a different facet of the same neural effect demonstrated here: higher activity in the low video-game group when inhibition (cognitive or spatial) was required, though the task goals differed. Firstperson shooter games reward improved onscreen visual perception, expanded spatial awareness, and quick reactions during violent interactions, which likely shift the brain's resources as well (Wu et al., 2012) - perhaps trading increased spatial awareness for decreased focus and less inhibition, for instance. Whether these effects are positive or negative outside of gameplay depends on the context: in the class- room, for instance, increased inhibition and decreased spatial awareness is helpful, but on the road, better spatial awareness to oncoming drivers may be more beneficial.

\section{Understanding the Long-Term Impact of Video Games on the Brain}

Results from this investigation align with previous research showing that playing a violent video game for a short duration results in lower prefrontal activity. Most notably, using an identical task as performed here, adolescents had reduced right prefrontal activity during inhibition immediately after playing a violent game for $30 \mathrm{~min}$, relative to a similarly exciting nonviolent game (Hummer et al., 2010). Likewise, experimental investigations have revealed decreased prefrontal activity during violent picture viewing (Engelhardt et al., 2011) or tasks requiring emotional control (Wang et al., 2009) following a violent video game. The present study also found reduced cerebellar activity during inhibition following video game play, which may be more directly involved in motor control, given that changes were on the right side, ipsilateral to the button-pressing hand.

$\mathrm{Wu}$ et al. (2012) conducted a "long-term" experimental investigation of how extensive play of a first-person shooter game (10 hours over a 3-week period) impacts brain function, using event-related potential (ERPs) recorded from the scalp. They found altered neural activity during a visuospatial attention task after extensive play only in those participants who improved on a task of spatial awareness, likely due to attentional control mechanisms. This study highlights the importance of examining individual differences in the effects of longterm game play, particularly on cortical control mechanisms.

To provide insight into the potential impact of long-term video game play on the brain, it is necessary to integrate the knowledge gained from controlled experiments of short- and relatively long-term (within a feasible duration) and from correlational and longitudinal research examining relationships between long-term play and neural structure and function. High past violent media exposure is associated with modified activity in portions of prefrontal cortex and anterior cingulate during inhibitory tasks (Kalnin et al., 2011; Mathews et al., 2005). Like- 
wise, frontal negative potentials during proactive cognitive control were diminished in individuals with higher past video game exposure (Bailey et al., 2010). In terms of brain structure, research has found lower orbitofrontal gray matter density (Strenziok et al., 2010) or fronto-parietal white matter volume (Hummer et al., 2014) with higher levels of past violent media exposure, which hint at long-term effects on the brain.

However, although longitudinal research has provided evidence that watching violent TV programs (Eron, Huesmann, Lefkowitz, \& Walder, 1972; Huesmann et al., 2003) or playing violent video games may have long-term effects on aggressive behavior (Gentile et al., 2014; Möller \& Krahé, 2009; Willoughby et al., 2012), no such study has been conducted on brain development. To better understand the neural effects of extensive video game play during youth, such longitudinal research measuring brain structure and function over many years can complement experimental studies such as the present investigation that last on the order of weeks to months.

This study marks a first step in this process, by identifying neural changes that occur after one week, with exploratory analyses suggesting that limited prior video game experience predicted larger changes to prefrontal function. Although efforts were made to gather sufficient samples to measure multiweek effects, necessary quality control measures reduced sample sizes for direct contrasts between groups. Although these measures provide more confidence in the validity of our data, with fewer subjects than anticipated we had less power to detect potential effects. Larger samples would be helpful to answer these important questions, including whether any long-term effects are mitigated as individuals become more accustomed to game play.

\section{Implications for Behavior}

The ultimate question of interest is not simply how the brain may be impacted, but rather what the long-term implications are for realworld behavior. From this study alone, we do not know precisely how video games impact behavior outside of gameplay, including the degree of behavioral changes, or in what contexts behavior may be affected. Diminished prefron- tal activity with extensive violent video game play may suggest a reduced capability for inhibition or, at least, a brain primed toward less top-down control. These changes can result in poorer regulation of emotion and behavior, particularly when physiological arousal is high, such as during an argument or physical altercation. This reactive, or impulsive, aggression occurs specifically as the result of provocation, as opposed to premeditated aggression. Attention problems and impulsivity are distinct factors from hostile worldviews and aggressive traits in reactive aggression (Swing \& Anderson, 2014). Thus, altered inhibition could be especially problematic for controlling impulsive aggression when combined with hostile behavioral scripts and views about others and the world (Anderson et al., 2003).

BRIEF scores indicate that measurable behavioral changes may have accompanied neural effects, which is noteworthy given the close connection of executive functions (including inhibition) to prefrontal cortex (Kane \& Engle, 2002; Miyake et al., 2000). After one week, the video game group reported an increase in executive function problems relative to the control group, including emotional control, indicating potential impairments in controlling aggressive thoughts or behaviors. This difference is due in part to a drop in reported dysfunction in the control group, although it is uncertain whether this decrease reflects an overall drop in the endorsement of problem behaviors upon repeated completions of the BRIEF questionnaire, or an improvement in executive function within the control group after refraining from all video game play.

However, the VG2 subsample reported fewer problems during their final visit, compared with those playing for one week (VG1 and $\mathrm{T}$ groups). Thus, the effect of extensive video game play on real-world executive functioning in this investigation is not totally clear. These discrepancies in the VG2 group may be somewhat due to an impact on self-awareness or self-monitoring (e.g., low endorsement of executive function difficulties due to poorer recall of behavior and/or quicker responding when completing the scale). Alternatively, maintaining consistent behavior patterns-such as a second straight week of violent game play or no game play-may minimize executive functioning problems in other areas by reducing prefrontal 
demands (e.g., stress, cognitive effort) compared with weekly changes in study requirements. Because violent video game play likely impacts neuropsychological functioning in a complex manner (i.e., not simply good or bad), future research should continue to employ methodology such as the BRIEF questionnaire that does not solely rely on computerized, visually demanding button-press tasks, to assess video games' influence on every-day functioning.

\section{Limitations and Future Directions}

As noted above, the most notable limitation is the lack of a nonviolent game during the first experimental week, which limits the conclusions about what aspects of gameplay are driving any effects. Given that action video games are known to alter measures of spatial attention (Dye et al., 2009; Green \& Bavelier, 2003), the field would benefit from examining how factors such as game strategy, pace, and character interactions influence the brain during subsequent cognitive and emotional processes. Understanding how these gameplay aspects interact to shape the brain must be a key focus moving forward, which can inform the development of media tools geared toward improving specific neurocognitive processes (e.g., attention, working memory, social cognition). For one, future work can use additional arms with high-action, nonviolent games or low-action violent games, to help delineate how specific game characteristics influence brain activity.

In addition, research is needed to clarify neural effects of cognitive training or "prosocial" video games that reward positive social interactions. Results here did not provide evidence that a working memory training game differs from simply avoiding game play, in terms of minimizing prior effects of violent video game on prefrontal function, although these results should be considered preliminary. Typically, working memory training paradigms require multiple weeks of practice (Jaeggi, Buschkuehl, Jonides, \& Perrig, 2008), whereas only one training week was used in the current study. There is evidence that several weeks of such training enhances prefrontal dopaminergic activity ( $\mathrm{McNab}$ et al., 2009), but additional research is needed to adequately address questions about the neurobiological impact of cognitive training paradigms, which may provide an important tool for addressing executive function impairments in clinical samples. Prosocial games, on the other hand, may have a more positive impact on social behaviors (Gentile et al., 2009; Greitemeyer \& Osswald, 2010).

There are several additional limitations to this study beyond those addressed above. First, this study employed a group of young adult males who were low in self-reported video game play. These young men were chosen so that video game play could be increased over normal levels, but this sample likely carries some self-selection characteristics, such as potentially less enjoyment of or captivation by video games than other populations. We also specifically targeted psychiatrically healthy men, who may have a different susceptibility to neural changes than populations of greater concern, such as those with aggressive traits. Future work must also include women, who generally spend less time playing violent video games, although understanding the impact of violent games on women's brains and behavior is similarly important. Likewise, the brains of younger samples may be more susceptible to various forms of media exposure. Investigating effects in child and adolescent samples is therefore highly recommended. Finally, although we had electronic confirmation of the duration of video game play or cognitive training, this investigation relied a great deal on selfreports to measure other media use, including whether play of other video games was avoided. Although to some degree these problems are unavoidable, multimethod approaches that integrate distinct sources of information to measure media exposure should be used in the future when feasible (Rich, Bickham, \& Shrier, 2015).

This investigation identified decreases in prefrontal activity during cognitive inhibition after one or two weeks of extensive violent video game play, suggesting a potential mechanism for how media violence exposure contributes to a subset of impulsive aggressive behaviors. Given society's increased engagement with interactive media programs, understanding the long-term impact of media characteristics on the brain is an increasingly important topic. 


\section{References}

Anderson, C. A., Berkowitz, L., Donnerstein, E., Huesmann, L. R., Johnson, J. D., Linz, D., . . . Wartella, E. (2003). The influence of media violence on youth. Psychological Science in the Public Interest, 4, 81-110.

Anderson, C. A., \& Bushman, B. J. (2001). Effects of violent video games on aggressive behavior, aggressive cognition, aggressive affect, physiological arousal, and prosocial behavior: A meta-analytic review of the scientific literature. Psychological Science, 12, 353-359. http://dx.doi.org/10.1111/ 1467-9280.00366

Anderson, C. A., \& Dill, K. E. (2000). Video games and aggressive thoughts, feelings, and behavior in the laboratory and in life. [Comparative Study Research Support, Non-U.S. Gov't]. Journal of Personality and Social Psychology, 78, 772-790. http://dx.doi.org/10.1037/0022-3514.78.4.772

Anderson, C. A., Shibuya, A., Ihori, N., Swing, E. L., Bushman, B. J., Sakamoto, A., . . . Saleem, M. (2010). Violent video game effects on aggression, empathy, and prosocial behavior in eastern and western countries: A meta-analytic review. Psychological Bulletin, 136, 151-173. http://dx.doi .org/10.1037/a0018251

Aron, A. R. (2007). The neural basis of inhibition in cognitive control. [Review]. The Neuroscientist: A Review Journal Bringing Neurobiology, Neurology and Psychiatry, 13, 214-228. http://dx.doi .org/10.1177/1073858407299288

Asahi, S., Okamoto, Y., Okada, G., Yamawaki, S., \& Yokota, N. (2004). Negative correlation between right prefrontal activity during response inhibition and impulsiveness: A fMRI study. [Comparative Study]. European Archives of Psychiatry and Clinical Neuroscience, 254, 245-251. http://dx.doi .org/10.1007/s00406-004-0488-z

Bailey, K., West, R., \& Anderson, C. A. (2010). A negative association between video game experience and proactive cognitive control. Psychophysiology, 47, 34-42. http://dx.doi.org/10.1111/j .1469-8986.2009.00925.x

Bailey, K., West, R., \& Kuffel, J. (2013). What would my avatar do? Gaming, pathology, and risky decision making. Frontiers in Psychology, 4, 609. http://dx.doi.org/10.3389/fpsyg.2013.00609

Barlett, C., Rodeheffer, C. D., Baldassaro, R., Hinkin, M. P., \& Harris, R. J. (2008). The effect of advances in video game technology and content on aggressive cognitions, hostility, and heart rate. $M e$ dia Psychology, 11, 540-565. Pii, 906858245.

Bartholow, B. D., \& Anderson, C. A. (2002). Effects of violent video games on aggressive behavior: Potential sex differences. Journal of Experimental Social Psychology, 38, 283-290. http://dx.doi.org/ 10.1006/jesp.2001.1502
Bartholow, B. D., Bushman, B. J., \& Sestir, M. A. (2006). Chronic violent video game exposure and desensitization to violence: Behavioral and eventrelated brain potential data. Journal of Experimental Social Psychology, 42, 532-539. http://dx.doi .org/10.1016/j.jesp.2005.08.006

Bartholow, B. D., Sestir, M. A., \& Davis, E. B. (2005). Correlates and consequences of exposure to video game violence: Hostile personality, empathy, and aggressive behavior. [Randomized Controlled Trial]. Personality and Social Psychology Bulletin, 31, 1573-1586. http://dx.doi.org/10 $.1177 / 0146167205277205$

Bavelier, D., Achtman, R. L., Mani, M., \& Föcker, J. (2012). Neural bases of selective attention in action video game players. [Research Support, N. I. H., Extramural]. Vision Research, 61, 132-143. http://dx.doi.org/10.1016/j.visres.2011.08.007

Boot, W. R., Kramer, A. F., Simons, D. J., Fabiani, M., \& Gratton, G. (2008). The effects of video game playing on attention, memory, and executive control. Acta Psychologica, 129, 387-398. http:// dx.doi.org/10.1016/j.actpsy.2008.09.005

Bushman, B. J., \& Anderson, C. A. (2002). Violent video games and hostile expectations: A test of the General Aggression Model. Personality and Social Psychology Bulletin, 28, 1679-1686. http://dx.doi .org/10.1177/014616702237649

Buysse, D. J., Reynolds, C. F., III, Monk, T. H., Berman, S. R., \& Kupfer, D. J. (1989). The Pittsburgh Sleep Quality Index: A new instrument for psychiatric practice and research. [Research Support, U.S. Gov't, P. H. S.]. Psychiatry Research, 28, 193-213. http://dx.doi.org/10.1016/01651781(89)90047-4

Chisholm, J. D., Hickey, C., Theeuwes, J., \& Kingstone, A. (2010). Reduced attentional capture in action video game players. [Research Support, Non-U.S. Gov't]. Attention, Perception and Psychophysics, 72, 667-671. http://dx.doi.org/10 .3758/APP.72.3.667

Cox, R. W. (1996). AFNI: Software for analysis and visualization of functional magnetic resonance neuroimages. Computers and Biomedical Research, 29, 162-173.

Dunlap, E. (2013). Trends in video game play through childhood, adolescence, and emerging adulthood. Psychiatry Journal, 2013, 1-7.

Dye, M. W., Green, C. S., \& Bavelier, D. (2009). The development of attention skills in action video game players. [Research Support, Non-U.S. Gov't]. Neuropsychologia, 47, 1780-1789. http:// dx.doi.org/10.1016/j.neuropsychologia.2009.02 .002

Engelhardt, C. R., Bartholow, B. D., Kerr, G. T., \& Bushman, B. J. (2011). This is your brain on violent video games: Neural desensitization to violence predicts increased aggression following vi- 
olent video game exposure. Journal of Experimental Social Psychology, 47, 1033-1036. http://dx .doi.org/10.1016/j.jesp.2011.03.027

Engelhardt, C. R., Hilgard, J., \& Bartholow, B. D. (2015). Acute exposure to difficult (but not violent) video games dysregulates cognitive control. Computers in Human Behavior, 45, 85-92. http:// dx.doi.org/10.1016/j.chb.2014.11.089

Eron, L. D., Huesmann, L. R., Lefkowitz, M. M., \& Walder, L. O. (1972). Does television violence cause aggression? American Psychologist, 27, 253-263. http://dx.doi.org/10.1037/h0033721

Ferguson, C. J., \& Kilburn, J. (2009). The public health risks of media violence: A meta-analytic review. The Journal of Pediatrics, 154, 759-763. http://dx.doi.org/10.1016/j.jpeds.2008.11.033

Gadow, K. D., Sprafkin, J., \& Weiss, M. D. (2004). Adult symptom inventory-4 manual. Stony Brook, NY: Checkmate Plus.

Gentile, D. A., Anderson, C. A., Yukawa, S., Ihori, N., Saleem, M., Ming, L. K., . . . Sakamoto, A. (2009). The effects of prosocial video games on prosocial behaviors: International evidence from correlational, longitudinal, and experimental studies. [Comparative Study Research Support, N. I. H., Extramural Research Support, Non-U.S. Gov't]. Personality and Social Psychology Bulletin, 35, 752-763. http://dx.doi.org/10.1177/ 0146167209333045

Gentile, D. A., Li, D., Khoo, A., Prot, S., \& Anderson, C. A. (2014). Mediators and moderators of long-term effects of violent video games on aggressive behavior: Practice, thinking, and action. Journal of the American Medical Association Pediatrics, 168, 450-457. Advance online publication. http://dx.doi.org/10.1001/jamapediatrics .2014 .63

Gentile, D. A., Swing, E. L., Lim, C. G., \& Khoo, A. (2012). Video game playing, attention problems, and impulsiveness: Evidence of bidirectional causality. Psychology of Popular Media Culture, 1, 62-70. http://dx.doi.org/10.1037/a0026969

Gioia, G. A. (2000). BRIEF: Behavior rating inventory of executive function: Professional manual. Psychological Assessment Resources.

Granvald, V., \& Marciszko, C. (2016). Relations between key executive functions and aggression in childhood. Child Neuropsychology, 22, 537-555.

Green, C. S., \& Bavelier, D. (2003). Action video game modifies visual selective attention. [Clinical Trial Research Support, Non-U.S. Gov't Research Support, U.S. Gov't, P. H. S.]. Nature, 423, 534537. http://dx.doi.org/10.1038/nature01647

Green, C. S., \& Bavelier, D. (2012). Learning, attentional control, and action video games. [Research Support, N. I. H., Extramural Research Support, U.S. Gov't, Non-P. H. S. Review]. Current Biol- ogy, 22, R197-R206. http://dx.doi.org/10.1016/j .cub.2012.02.012

Greitemeyer, T., \& Mügge, D. O. (2014). Video games do affect social outcomes: A meta-analytic review of the effects of violent and prosocial video game play. Personality and Social Psychology Bulletin, 40, 578-589. http://dx.doi.org/10.1177/ 0146167213520459

Greitemeyer, T., \& Osswald, S. (2010). Effects of prosocial video games on prosocial behavior. Journal of Personality and Social Psychology, 98, 211-221. http://dx.doi.org/10.1037/a0016997

Guo, X., Zheng, L., Wang, H., Zhu, L., Li, J., Wang, Q., . . . Yang, Z. (2013). Exposure to violence reduces empathetic responses to other's pain. Brain and Cognition, 82, 187-191. http://dx.doi .org/10.1016/j.bandc.2013.04.005

Hofmann, W., Schmeichel, B. J., \& Baddeley, A. D. (2012). Executive functions and self-regulation. Trends in Cognitive Sciences, 16, 174-180. http:// dx.doi.org/10.1016/j.tics.2012.01.006

Huesmann, L. R., Moise-Titus, J., Podolski, C.-L., \& Eron, L. D. (2003). Longitudinal relations between children's exposure to TV violence and their aggressive and violent behavior in young adulthood: 1977-1992. Developmental Psychology, 39, 201221. http://dx.doi.org/10.1037/0012-1649.39.2 .201

Hummer, T. A., Kronenberger, W. G., Wang, Y., Anderson, C. C., \& Mathews, V. P. (2014). Association of television violence exposure with executive functioning and white matter volume in young adult males. Brain and Cognition, 88, 2634. http://dx.doi.org/10.1016/j.bandc.2014.04.010

Hummer, T. A., Wang, Y., Kronenberger, W. G., Mosier, K. M., Kalnin, A. J., Dunn, D. W., \& Mathews, V. P. (2010). Short-term violent video game play by adolescents alters prefrontal activity during cognitive inhibition. Media Psychology, 13, 136-154. http://dx.doi.org/10.1080/1521326100 3799854Pii923001300

Huttenlocher, P. R. (1979). Synaptic density in human frontal cortex - developmental changes and effects of aging. [Research Support, U.S. Gov't, P. H. S.]. Brain Research, 163, 195-205. http://dx .doi.org/10.1016/0006-8993(79)90349-4

Jaeggi, S. M., Buschkuehl, M., Jonides, J., \& Perrig, W. J. (2008). Improving fluid intelligence with training on working memory. [Research Support, N. I. H., Extramural Research Support, Non-U.S. Gov't Research Support, U.S. Gov't, Non-P. H. S.]. Proceedings of the National Academy of Sciences of the United States of America, 105, 68296833. http://dx.doi.org/10.1073/pnas.0801268105

Kalnin, A. J., Edwards, C. R., Wang, Y., Kronenberger, W. G., Hummer, T. A., Mosier, K. M., . . . Mathews, V. P. (2011). The interacting role of media violence exposure and aggressive-disruptive 
behavior in adolescent brain activation during an emotional Stroop task. [Research Support, N. I. H., Extramural Research Support, Non-U.S. Gov't]. Psychiatry Research, 192, 12-19. http://dx.doi .org/10.1016/j.pscychresns.2010.11.005

Kane, M. J., \& Engle, R. W. (2002). The role of prefrontal cortex in working-memory capacity, executive attention, and general fluid intelligence: An individual-differences perspective. Psychonomic Bulletin and Review, 9, 637-671. http://dx .doi.org/10.3758/BF03196323

Kaufman, A. S., \& Kaufman, N. L. (2004). Kaufman brief intelligence test (2nd ed.). Circle Pines, MN: American Guidance Service.

Kelly, C. R., Grinband, J., \& Hirsch, J. (2007). Repeated exposure to media violence is associated with diminished response in an inhibitory frontolimbic network. [Research Support, Non-U.S. Gov't]. PLoS One, 2, e1268. http://dx.doi.org/10 .1371/journal.pone.0001268

Konishi, S., Nakajima, K., Uchida, I., Kikyo, H., Kameyama, M., \& Miyashita, Y. (1999). Common inhibitory mechanism in human inferior prefrontal cortex revealed by event-related functional MRI. Brain: A Journal of Neurology, 122, 981-991. http://dx.doi.org/10.1093/brain/122.5.981

Kronenberger, W. G., Mathews, V. P., Dunn, D. W., Wang, Y., Wood, E. A., Giauque, A. L., . . . Li, T. Q. (2005a). Media violence exposure and executive functioning in aggressive and control adolescents. Journal of Clinical Psychology, 61, 725737. http://dx.doi.org/10.1002/jclp.20022

Kronenberger, W. G., Mathews, V. P., Dunn, D. W., Wang, Y., Wood, E. A., Larsen, J. J., . . . Lurito, J. T. (2005b). Media violence exposure in aggressive and control adolescents: Differences in selfand parent-reported exposure to violence on television and in video games. Aggressive Behavior, 31, 201-216. http://dx.doi.org/10.1002/ab.20021

Lebel, C., Walker, L., Leemans, A., Phillips, L., \& Beaulieu, C. (2008). Microstructural maturation of the human brain from childhood to adulthood. [Research Support, Non-U.S. Gov't]. NeuroImage, 40, 1044-1055. http://dx.doi.org/10.1016/j.neuroimage.2007.12.053

Lefkowitz, M. M., Eron, L. D., Walder, L. O., \& Huesmann, L. R. (1977). Growing up to be violent: A longitudinal study of the development of aggression. New York, NY: Pargamon Press.

Lenhart, A., Kahne, J., Middaugh, E., Macgill, A. R., Evans, C., \& Vitak, J. (2008). Teens, video games, and civics: teens' gaming experiences are diverse and include significant social interaction and civic engagement. Pew Internet \& American Life Project.

Liddle, P. F., Kiehl, K. A., \& Smith, A. M. (2001). Event-related fMRI study of response inhibition. [pii]. Human Brain Mapping, 12, 100-109. http://dx .doi.org/10.1002/1097-0193(200102)12:2<100:: AID-HBM1007>3.0.CO;2-6

Luijten, M., Meerkerk, G. J., Franken, I. H., van de Wetering, B. J., \& Schoenmakers, T. M. (2015). An fMRI study of cognitive control in problem gamers. Psychiatry Research, 231, 262-268. http://dx.doi.org/10.1016/j.pscychresns.2015.01 .004

Mathews, V. P., Kronenberger, W. G., Wang, Y., Lurito, J. T., Lowe, M. J., \& Dunn, D. W. (2005). Media violence exposure and frontal lobe activation measured by functional magnetic resonance imaging in aggressive and nonaggressive adolescents. Journal of Computer Assisted Tomography, 29, 287-292. http://dx.doi.org/10.1097/01.rct .0000162822 .46958 .33

McNab, F., Varrone, A., Farde, L., Jucaite, A., Bystritsky, P., Forssberg, H., \& Klingberg, T. (2009). Changes in cortical dopamine D1 receptor binding associated with cognitive training. [Research Support, Non-U.S. Gov't]. Science, 323, 800-802. http://dx.doi.org/10.1126/science.1166102

Mishra, J., Zinni, M., Bavelier, D., \& Hillyard, S. A. (2011). Neural basis of superior performance of action videogame players in an attention-demanding task. [Research Support, N. I. H., Extramural Research Support, U.S. Gov't, Non-P. H. S.]. The Journal of Neuroscience, 31, 992-998. http://dx .doi.org/10.1523/JNEUROSCI.4834-10.2011

Miyake, A., Friedman, N. P., Emerson, M. J., Witzki, A. H., Howerter, A., \& Wager, T. D. (2000). The unity and diversity of executive functions and their contributions to complex "Frontal Lobe" tasks: A latent variable analysis. Cognitive Psychology, 41, 49-100. http://dx.doi.org/10.1006/cogp.1999 .0734

Möller, I., \& Krahé, B. (2009). Exposure to violent video games and aggression in German adolescents: A longitudinal analysis. Aggressive Behavior, 35, 75-89. http://dx.doi.org/10.1002/ab.20290

Munakata, Y., Herd, S. A., Chatham, C. H., Depue, B. E., Banich, M. T., \& O'Reilly, R. C. (2011). A unified framework for inhibitory control. Trends in Cognitive Sciences, 15, 453-459. http://dx.doi .org/10.1016/j.tics.2011.07.011

Nielsen. (2014). The digital consumer, February 2014. New York, NY: The Nielsen Company.

Ochsner, K. N., \& Gross, J. J. (2005). The cognitive control of emotion. [Research Support, N. I. H., Extramural Research Support, U.S. Gov't, Non-P. H. S. Research Support, U.S. Gov't, P. H. S. Review]. Trends in Cognitive Sciences, 9, 242-249. http://dx.doi.org/10.1016/j.tics.2005.03.010

Olson, C. K. (2010). Children's motivations for video game play in the context of normal development. Review of General Psychology, 14, 180-187. http://dx.doi.org/10.1037/a0018984 
Paik, H., \& Comstock, G. (1994). The effects of television violence on antisocial-behavior - A metaanalysis. Communication Research, 21, 516546. http://dx.doi.org/10.1177/009365094021 004004

Pliszka, S. R., Liotti, M., \& Woldorff, M. G. (2000). Inhibitory control in children with attentiondeficit/hyperactivity disorder: Event-related potentials identify the processing component and timing of an impaired right-frontal response-inhibition mechanism. [Research Support, Non-U.S. Gov't]. Biological Psychiatry, 48, 238-246. http://dx.doi .org/10.1016/S0006-3223(00)00890-8

Poland, S. E., Monks, C. P., \& Tsermentseli, S. (2015). Cool and hot executive function as predictors of aggression in early childhood: Differentiating between the function and form of aggression. British Journal of Developmental Psychology. Advance online publication.

Powers, K. L., Brooks, P. J., Aldrich, N. J., Palladino, M. A., \& Alfieri, L. (2013). Effects of video-game play on information processing: A meta-analytic investigation. [Meta-Analysis Research Support, Non-U.S. Gov't]. Psychonomic Bulletin \& Review, 20, 1055-1079. http://dx.doi.org/10.3758/s13423013-0418-z

Rich, M., Bickham, D. S., \& Shrier, L. A. (2015). Measuring Youth Media Exposure: A Multimodal Method for Investigating the Influence of Media on Digital Natives. American Behavioral Scientist, 59, 1736-1754. http://dx.doi.org/10.1177/ 0002764215596558

Rideout, V. J., Foehr, U. G., \& Roberts, D. F. (2010). Generation M2: Media in the lives of 8- to 18year-olds. Menlo Park, CA: The Henry J. Kaiser Family Foundation.

Rubia, K., Smith, A. B., Brammer, M. J., Toone, B., \& Taylor, E. (2005). Abnormal brain activation during inhibition and error detection in medication-naive adolescents with ADHD. [Comparative Study Research Support, Non-U.S. Gov't]. The American Journal of Psychiatry, 162, 1067-1075. http://dx.doi.org/10.1176/appi.ajp.162.6.1067

Sherry, J. L. (2001). The effects of violent video games on aggression - A meta-analysis. Human Communication Research, 27, 409-431.

Sowell, E. R., Thompson, P. M., Holmes, C. J., Jernigan, T. L., \& Toga, A. W. (1999). In Vivo evidence for post-adolescent brain maturation in frontal and striatal regions. [Clinical Trial Controlled Clinical Trial Letter Research Support, U.S. Gov't, P. H. S.]. Nature Neuroscience, 2, 859861. http://dx.doi.org/10.1038/13154

Spence, I., \& Feng, J. (2010). Video games and spatial cognition. Review of General Psychology, 14, 92-104. http://dx.doi.org/10.1037/a0019491

Strenziok, M., Krueger, F., Deshpande, G., Lenroot, R. K., van der Meer, E., \& Grafman, J. (2011).
Fronto-parietal regulation of media violence exposure in adolescents: A multi-method study. [Research Support, N. I. H., Intramural]. Social Cognitive and Affective Neuroscience, 6, 537-547. http://dx.doi.org/10.1093/scan/nsq079

Strenziok, M., Krueger, F., Pulaski, S. J., Openshaw, A. E., Zamboni, G., van der Meer, E., \& Grafman, J. (2010). Lower lateral orbitofrontal cortex density associated with more frequent exposure to television and movie violence in male adolescents. The Journal of Adolescent Health, 46, 607-609. http://dx.doi.org/10.1016/j.jadohealth.2009.11.196

Swick, D., Ashley, V., \& Turken, U. (2011). Are the neural correlates of stopping and not going identical? Quantitative meta-analysis of two response inhibition tasks. NeuroImage, 56, 1655-1665. http://dx.doi.org/10.1016/j.neuroimage.2011.02 .070

Swing, E. L., \& Anderson, C. A. (2014). The role of attention problems and impulsiveness in media violence effects on aggression. Aggressive Behavior, 40, 197-203. Advance online publication. http://dx.doi.org/10.1002/ab.21519

Talairach, J., \& Tournoux, P. (1988). Co-planar stereotaxic atlas of the human brain. 3-Dimensional proportional system: An approach to cerebral imaging. Stuttgart: Thieme.

Tunbridge, E. M., Weickert, C. S., Kleinman, J. E., Herman, M. M., Chen, J., Kolachana, B. S., . . . Weinberger, D. R. (2007). Catechol-o-methyltransferase enzyme activity and protein expression in human prefrontal cortex across the postnatal lifespan. [Research Support, Non-U.S. Gov't]. Cerebral Cortex, 17, 1206-1212. http://dx.doi.org/10 $.1093 /$ cercor/bhl032

Uhlmann, E., \& Swanson, J. (2004). Exposure to violent video games increases automatic aggressiveness. [Research Support, Non-U.S. Gov't Research Support, U.S. Gov't, Non-P. H. S.]. Journal of Adolescence, 27, 41-52. http://dx.doi.org/10 .1016/j.adolescence.2003.10.004

Van den Bergh, F., Spronk, M., Ferreira, L., Bloemarts, E., Groenink, L., Olivier, B., \& Oosting, R. (2006). Relationship of delay aversion and response inhibition to extinction learning, aggression, and sexual behaviour. Behavioural Brain Research, 175, 75-81. http://dx.doi.org/10.1016/j .bbr.2006.08.003

Vigil-Colet, A., \& Codorniu-Raga, M. J. (2004). Aggression and inhibition deficits, the role of functional and dysfunctional impulsivity. Personality and Individual Differences, 37, 1431-1440. http:// dx.doi.org/10.1016/j.paid.2004.01.013

Wang, Y., Mathews, V. P., Kalnin, A. J., Mosier, K. M., Dunn, D. W., Saykin, A. J., \& Kronenberger, W. G. (2009). Short term exposure to a violent video game induces changes in frontolim- 
bic circuitry in adolescents. Brain Imaging and Behavior. E-pub.

Willoughby, T., Adachi, P. J., \& Good, M. (2012). A longitudinal study of the association between violent video game play and aggression among adolescents. [Research Support, Non-U.S. Gov't]. Developmental Psychology, 48, 1044-1057. http://dx .doi.org/10.1037/a0026046

Wu, S., Cheng, C. K., Feng, J., D’Angelo, L., Alain, C., \& Spence, I. (2012). Playing a first-person shooter video game induces neuroplastic change. [Randomized Controlled Trial Research Support, Non-U.S. Gov't]. Journal of Cognitive Neurosci- ence, 24, 1286-1293. http://dx.doi.org/10.1162/ jocn_a_00192

Yang, H., Wu, Q. Z., Guo, L. T., Li, Q. Q., Long, X. Y., Huang, X. Q., . . . Gong, Q. Y. (2011). Abnormal spontaneous brain activity in medication-naïve ADHD children: A resting state fMRI study. [Controlled Clinical Trial]. Neuroscience Letters, 502, 89-93. http://dx.doi.org/10.1016/j .neulet.2011.07.028

Received May 16, 2016

Revision received October 21, 2016 Accepted October 26, 2016 